\title{
RAPD em Pau-rosa (Aniba rosaeodora Ducke): adaptaçáo do método para coleta de amostras in situ, ajuste das condiçóes de PCR e apresentação de um processo para selecionar bandas reprodutíveis ${ }^{1}$
}

\author{
Ronaldo Pereira SANTOS²; Paula Cristina da Silva ANGELO³; Regina Caetano QUISEN³ Christiane \\ Lopes OLIVEIRA4; Paulo de Tarso Barbosa SAMPAIO5
}

\begin{abstract}
RESUMO
O Pau-rosa (Aniba rosaeodora Ducke) é uma espécie importante economicamente para a Região Amazônica, porque sua madeira é fonte de linalol, insumo utilizado pelas perfumarias. Esta espécie foi explorada durante décadas e, ainda assim, o conhecimento acerca da diversidade genética intra-específica é muito restrito. Foram objetivos deste trabalho: 1) validar um protocolo para coleta de folhas de pau-rosa que permitisse preservar a integridade do DNA até a estocagem em "freezer"; 2) selecionar um protocolo para extração de DNA em quantidade e qualidade adequadas para geração de bandas RAPD e 3) desenvolver um critério para avaliar o grau de reprodutibilidade que pudesse auxiliar a seleção de bandas RAPD úteis para análises de diversidade genética. Imediatamente após a coleta, as folhas foram acondicionadas em tubos de polietileno com sílica gel e aí permaneceram por até 10 dias. Foram testados três protocolos para a extração de ácidos nucléicos destas folhas, condições ideais para as PCR e a reprodutibilidade dos padrōes RAPD. Critérios para a eliminação das bandas que mais contribuíram para o afastamento dos resultados do ideal da reprodutibilidade total foram desenvolvidos e a significância estatística das diferenças geradas pela aplicação dos critérios ao conjunto de dados foi testada. DNA com qualidade e em quantidade suficiente para a geração de padrōes RAPD, nas condiçōes ideais definidas para as PCRs, foi obtido. A eliminação de bandas com reprodutibilidade menor que $70 \%$ não diferiu do controle. A eliminação de bandas com reprodutibilidade menor que $90 \%$ diferiu dos demais tratamentos em todos os arranjos testados $(\mathrm{P} \leq 5 \%)$.
\end{abstract}

PALAVRAS-CHAVE

RAPD, reprodutibilidade, marcadores moleculares, Amazônia

\section{RAPD in Rosewood (Aniba rosaeodora Ducke): adequation of a method for in situ sample collecting, PCR adjustments and presentation of a procedure to select reproducible amplified fragments}

\begin{abstract}
Rosewood (Aniba rosaeodora Ducke) is one of the economically valuable species in the Amazon region, because it is the principal source of linalool which is demanded by the perfumery industry. This species was submitted to hard exploitation along the past decades and besides this almost nothing is known about its intraspecific genetic diversity. The objectives of this work were: 1) to validate a method to collect rosewood leaves, while preserving the integrity of DNA until storage in freezer; 2) to choose a method for extraction of nucleic acids in quantity and with quality good enough to be used for RAPD and 3) to develop criteria for evaluating the reproducibility, which could help to select RAPD bands useful for genetic diversity analysis. Immediately following collection, the leaves were put in PET flasks partially filled with silica gel and kept there up to 10 days. Three methods for extracting nucleic acids from those leaves, the PCR conditions and the reproducibility of the RAPD patterns produced were tested. Criteria for elimination of bands that contributed to maintain reproducibility away from the ideal, which would be total reproducibility, were developed and the differences produced by application of these criteria were statically tested. DNA with sufficient quality to generate RAPD patterns under the improved conditions defined for the PCRs was obtained. Elimination of bands with reproducibility below $70 \%$ did not differ from control. Elimination of bands with reproducibility below $90 \%$ differed from all the other treatments tested $(P \leq 5 \%)$.
\end{abstract}

\section{KEYWORDS}

$R A P D$, reproducibility, molecular markers, Amazon

\footnotetext{
1 Trabalho é parte da Dissertação do primeiro autor, junto à Coordenação de Ciências de Florestas Tropicais do Instituto Nacional de Pesquisa da Amazônia (INPA).

${ }^{2}$ Mestre em Ciências de Florestas Tropicais, Bolsista do Programa Internacional de Pós-graduação da Fundação Ford. E-mail: ronaldo.santos@mns.incra.gov.br.

3 Pesquisadora III, D.Sc., Embrapa Amazônia Ocidental, Rod. AM 010 - km 29, Zona Rural, CP 319, Manaus - AM, CEP 69010-970. e-mail: paula@cpaa.embrapa.br.

4 Bolsista PIBIC/CNPq, estagiária na Embrapa Amazônia Ocidental até julho de 2004.

5 Pesquisador, INPA, Alameda Cosme Ferreira, 1756, Aleixo, CP 478, Manaus - AM, CEP 69011-970. e-mail: sampaio@inpa.gov.br.
} 


\section{INTRODUÇÃO}

O pau-rosa (Aniba rosaeodora Ducke) é uma espécie arbórea importante para a região Amazônica por causa do alto valor do linalol, componente majoritário do óleo essencial extraído da planta e utilizado pela indústria de perfumaria (Vial-Debas, 2000). Ocorre em toda a Floresta Amazônica de terra-firme, com freqüência muito baixa atualmente (Mitja \& Lescure, 2000), em função de décadas de exploração não controlada, durante as quais, boa parte das populaçôes naturais foi dizimada (Vial-Debas, 2000). Isto justificou sua inserção na lista de espécies ameaçadas de extinção (IBAMA, 1992; Vial-Debas, 2000). A exploração sem planejamento pode ter contribuído para a redução da diversidade genética intra-específica (Hall et al., 1996; Young et al., 1996), assunto, apesar de relevante, pouquíssimo explorado para esta espécie.

As possibilidades de quantificação da diversidade genética, do fluxo gênico e a análise da estrutura genética de populaçôes, tornaram-se mais concretas, nas últimas décadas (Gerburek, 1997) a partir do desenvolvimento de técnicas que permitem as análises genéticas a nível molecular (Almeida et al., 2001). Dentre estas técnicas, destacam-se os marcadores moleculares baseados em amplificação de DNA via PCR (polymerase chain reaction), desenvolvidos por Mullis \& Faloona (1987). O surgimento de procedimentos apoiados em PCR, como o RAPD (random amplified polymorphic DNA), desenvolvido por Williams et al. (1990), possibilitou o estudo de espécies sobre as quais se dispõe de pouca informação prévia, quando recursos financeiros e tempo, por exemplo, são fatores limitantes (Ferreira \& Grattapaglia, 1994).

Além de ser relativamente fácil, rápida e simples, a aplicação de RAPD tem custo mais baixo que os demais marcadores e evidencia um bom número de loci polimórficos por reação, distribuídos aleatoriamente pelo genoma (Ferreira \& Grattapaglia, 1994). Algumas das limitaçōes da técnica, como o fato de serem marcadores dominantes, tem sido compensadas por metodologias alternativas de análise dos dados (Clark \& Laningan, 1993; Lynch \& Milligan, 1994; Bussel, 1999). Por outro lado, a reprodutibilidade dos ensaios depende da espécie analisada, do executor dos experimentos, da qualidade dos reagentes e da estabilidade do termociclador (Yu \& Pauls, 1992; Meunier \& Grimont, 1993; Grattapaglia, 1997; Jones et al., 1997). Assim, a otimização e padronização das condições de realização da PCR e a avaliação do grau de reprodutibilidade dos resultados são essenciais (Williams et al., 1990; Yu \& Pauls, 1992; Grattapaglia, 1997; Jones et al., 1997).

Os objetivos deste trabalho foram: (1) validar um método para a coleta de material vegetal de pau-rosa; (2) selecionar um método para a extração de DNA de folhas de Pau-rosa, em quantidade e com qualidade adequadas para a obtenção de padrôes RAPD e (3) desenvolver e validar um critério, baseado no grau de reprodutibilidade, para selecionar bandas RAPD para as análises genéticas.

\section{MATERIAL E MÉTODOS}

\section{COLETA DO MATERIAL VEGETAL}

Folhas jovens coletadas de dez plantas de pau-rosa mantidas na Embrapa Amazônia Ocidental (Manaus/AM) e de 130 plantas, matrizes (adultas, em idade reprodutiva) e regenerantes (juvenis), de população natural da Reserva Florestal Adolpho Ducke (Manaus/AM) foram acondicionadas em tubos de polietileno contendo sílica gel (Chase \& Hills, 1991). As folhas coletadas na Sede da Embrapa foram armazenadas imediatamente a $-20^{\circ} \mathrm{C}$, no Laboratório de Biologia Molecular. As folhas coletadas na Reserva Florestal Adolpho Ducke, a $26 \mathrm{~km}$ ao norte do centro da cidade de Manaus, permaneceram em temperatura ambiente, nos tubos com sílica, de sete a 10 dias, até serem armazenadas a $20^{\circ} \mathrm{C}$, no laboratório.

\section{EXTRAÇÃO E QUANTIFICAÇÃO DE ÁCIDOS NUCLÉICOS}

$\mathrm{O}$ material vegetal foi submetido à extração dos ácidos nucléicos, segundo três protocolos: Doyle \& Doyle (1987), Edwards et al. (1991) e Khanuja et al. (1999). As soluçōes de ácidos nucléicos, contendo o DNA genômico, foram armazenadas a $-20^{\circ} \mathrm{C}$, em TE. Uma vez que as folhas foram mantidas por até 10 dias à temperatura ambiente antes da preservação em freezer, os protocolos de extração foram avaliados com relação às propriedades de preservar a integridade do DNA extraído. A integridade do DNA foi examinada após a realização de eletroforese em géis de agarose a $1 \%$. A quantificação e a análise de pureza dos ácidos nucléicos extraídos foram realizadas através da leitura de absorvâncias (GeneQuant pro RNA/DNA calculator, Amersham/Pharmacia) verificadas nos comprimentos de onda de $260 \mathrm{~nm}$ e de $280 \mathrm{~nm}$.

\section{APRIMORAMENTO DAS CONDIÇÕES DA PCR}

As soluçōes de ácidos nucléicos foram diluídas para a concentração de $10 \mathrm{ng} \cdot \mathrm{ml}^{-1}$ em água destilada autoclavada e armazenadas a $-20^{\circ} \mathrm{C}$. Foram testadas diferentes concentrações finais de DNA, $\mathrm{MgCl}_{2}$, primers, dNTPs e Taq DNA polimerase, mantendo inalteradas as concentrações do $\mathrm{KCl}(50 \mathrm{mM})$ e do Tris-HCl $(20 \mathrm{mM})$ utilizados nas reações. Concentrações de DNA iguais a $0,15,30,45$ e $60 ; 0 ; 1,25 ; 2,50 ; 3,75$ e 5,00 unidades de Taq DNA polimerase; 0; 0,75; 1,50; 2,25 e 3,00 $\mathrm{mM}$ de $\mathrm{MgCl}_{2} ; 0,125,250,375,500 \mathrm{nM}$ de "primer" decâmero e $0,50,100,150$ e $200 \mu \mathrm{M}$ de cada um dos dNTPs foram testados, em reações de $25 \mathrm{~mL}$. A necessidade de inclusão de BSA (soroalbumina bovina) a 0,1\% também foi testada. Os testes para aprimoramento das PCR foram realizados utilizando o primer de seqüência 5'- ACG GCG TAT G - 3', DNA extraído de uma planta de pau-rosa e o termociclador (Perkin Elmer Gene Amp PCR System 2400) programado para $92^{\circ} \mathrm{C}$ 
por $1 \mathrm{~min} ; 35 \mathrm{x}\left(92^{\circ} \mathrm{C}\right.$ por $1 \mathrm{~min} ; 30^{\circ} \mathrm{C}$ por 2 min e $72^{\circ} \mathrm{C}$ por $1 \mathrm{~min}) ; 72{ }^{\circ} \mathrm{C}$ por $5 \mathrm{~min}$ e $4{ }^{\circ} \mathrm{C}$ por tempo indefinido. $\mathrm{A}$ eletroforese foi realizada em géis de agarose a 1,5\% em TBE $1 \mathrm{X}$, corados com brometo de etídio $\left(0,5 \mu \mathrm{g} \cdot \mathrm{ml}^{-1}\right)$, a cerca de $5 \mathrm{~V} . \mathrm{cm}^{-}$ ${ }^{1}$ de gel, 200 a $250 \mathrm{~mA}$, durante 3 horas. $\mathrm{O}$ registro dos resultados foi realizado utilizando sistema de foto-documentação KODAK (câmera digital DC120 e aplicativos acessórios). As tabelas de dados binários (1 para a presença de banda e 0 para a ausência) foram construídas segundo o exame visual das imagens, em formato KODAK (extensão .bip), depois de impressas. As melhores condições encontradas foram aplicadas a reaçóes com o DNA de quatro plantas utilizando 20 primers para o estudo inicial do polimorfismo RAPD para o pau-rosa.

\section{AVALIAÇÃO DO GRAU DE REPRODUTIBILIDADE DAS BANDAS RAPD}

Foi avaliado o grau de reprodutibilidade das bandas produzidas, em condições aprimoradas, usando 11 primers decâmeros, com conteúdo de pares de bases GC acima de 50\%, que foram utilizados em reações de PCR com: a) o DNA de um número variável de plantas ( 2 primers $\mathrm{x}$ DNA de 20 plantas +9 primers $\mathrm{x}$ DNA de 8 plantas $=112$ padrões RAPD) e b) o DNA de um número constante de plantas ( 11 primers $\mathrm{x}$ DNA de 8 plantas $=88$ padrōes RAPD). Este último arranjo foi organizado escolhendo aleatoriamente 8 de cada um dos dois grupos de 20 padrôes produzidos em a e mantendo os nove grupos de 8 padrōes no formato original. As 112 reaçôes de PCR foram realizadas em duas ocasiōes (total de 224 padrões RAPD), por um mesmo executor, mantendo constantes os estoques de reagentes e equipamentos utilizados. Comparou-se banda a banda, os conjuntos de padrões RAPD produzidos nas duas ocasiōes, verificando o número de coincidências ocorridas. Tratando-se de experimentos realizados com o DNA de 20 plantas (Figura 1), havia 20 chances de coincidência para cada banda do padrão (banda presente na primeira e na segunda ocasióes ou ausente na primeira e na segunda ocasiōes em que o DNA de cada uma das 20 plantas foi utilizado para a PCR). A porcentagem de coincidências poderia variar desde 0 em 20 (grau de reprodutibilidade $=0$ ) até 20 coincidências em 20 chances (grau de reprodutibilidade $=100 \%$ ) para cada banda.

\section{DEFINIÇÃO E VALIDAÇÃO DO CRITÉRIO DE SELEÇÃO DE BANDAS COM BASE NA REPRODUTIBILIDADE}

O número observado de índices (Coeficiente de Jaccard) de auto-similaridade, ou seja, de similaridade entre padróes RAPD obtidos para a mesma planta em duas PCR (Pérez et al., 1998), foi utilizado para detectar diferenças entre os conjuntos de padrôes RAPD produzidos na primeira e na segunda ocasião em que as 112 PCR foram realizadas. Quatro tratamentos foram dispensados aos conjuntos de 112 padrões RAPD (número variável de plantas) e aos conjuntos de 88 padrōes RAPD (número constante de plantas), sendo: Tratamento 1 (controle)
- nenhum critério de reprodutibilidade foi aplicado, ou seja, todas as bandas de todos os padrões RAPD foram admitidas para o cálculo dos índices de auto-similaridade; Tratamento 2 - apenas bandas com grau de reprodutibilidade acima de $90 \%$ foram admitidas como componentes dos padrōes RAPD para o cálculo dos índices de auto-similaridade; Tratamento 3 - apenas bandas com grau de reprodutibilidade acima de $80 \%$ foram admitidas como componentes dos padróes RAPD para o cálculo dos índices de auto-similaridade e Tratamento 4 - apenas bandas com grau de reprodutibilidade acima de $70 \%$ foram admitidas como componentes dos padróes RAPD para o cálculo dos índices de auto-similaridade. O número total de índices de auto-similaridade iguais a 1 (significando que o padrão RAPD produzido foi exatamente o mesmo nas duas ocasiōes em que DNA de uma planta foi utilizado para a PCR em presença do mesmo primer), observado no conjunto de padrôes produzidos por cada um de 11 primers avaliados, foi contado. O número médio de índices com valor 1 (número de índices de auto-similaridade com valor $1 /$ número total de índices de auto-similaridade no conjunto de padrôes RAPD gerados por cada primer) foi calculado, para cada tratamento. Para verificar a existência de diferenças estatisticamente significativas entre os tratamentos foi realizada a

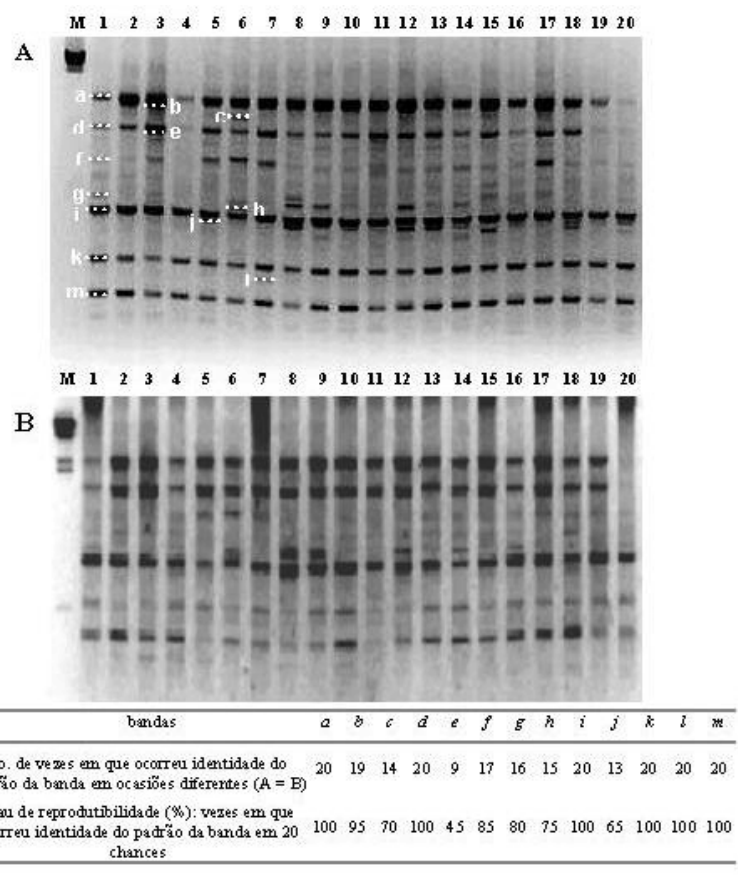

Figura 1 - Padrão de bandas RAPD para Pau-rosa (A. rosaeodora Ducke) 0 DNA de 20 plantas foi amplificado, em duas ocasiões diferentes (A e B). Os números (1 a 20) identificam os padrões referentes a cada planta. As letras (de a a $m$ ) identificam as bandas que compõem os padrões RAPD. Bandas em A foram comparadas com bandas em B para determinar seu grau de reprodutibilidade, que está indicado na tabela abaixo das imagens dos géis de agarose. M - I/Hind III (Embrapa Amazônia Ocidental - Manaus/ AM). 
análise de variância e para testar os contrastes entre as médias aplicou-se o Teste de Tukey, utilizando o aplicativo SYSTAT, versão 9. Os índices de auto-similaridade (Coeficiente de Jaccard) foram calculados utilizando o programa GENES (Cruz, 2001).

A correlação entre matrizes de similaridade tradicionais (Coeficientes de Jaccard) também foi utilizada para detectar diferenças entre os tratamentos de seleção de bandas segundo o grau de reprodutibilidade que foram dispensados aos dois conjuntos de 88 padróes RAPD, produzidos em ocasiōes diferentes. Das tabelas de dados binários foram, conforme cada um dos critérios de reprodutibilidade (tratamentos), selecionadas bandas "úteis" e produziram-se duas matrizes para cada conjunto de dados: uma referente à primeira ocasião em que as PCR foram realizadas e outra referente à segunda ocasião. $O$ teste de correlação entre as duas matrizes de similaridade geradas para cada um dos quatro tratamentos foi realizado através da rotina "MXCOMPG" do aplicativo NTSYS - PC, versão 1.60 obtendo-se os valores de correlação e as probabilidades foram calculadas pelo teste de Mantel.

\section{LISTAGEM DE ABREVIATURAS UTILIZADAS}

$$
\text { TE: tampão Tris-EDTA }
$$

PCR: "polymerase chain reaction"

dNTPs: deoxinucleotídeos trifosfato

BSA: soroalbumina bovina

TBE: tampão Tris-Borato-EDTA

RAPD: "random amplified polymorphic DNA"

\section{RESULTADOS E DISCUSSÃO}

Três protocolos para a extração de ácidos nucléicos de folhas de pau-rosa foram testados e os testes permitiram, também, validar o método utilizado para a coleta e preservação do material vegetal. As folhas coletadas tanto na Embrapa Amazônia Ocidental quanto na Reserva Florestal Adolpho Ducke, forneceram DNA em quantidade e com qualidade suficientes para a realização dos experimentos de RAPD-PCR, quando o protocolo desenvolvido por Edwards et al. (1991) foi utilizado para a extração. Folhas coletadas na Reserva Ducke ficaram, por cerca de 10 dias, em temperatura ambiente antes de serem armazenadas a $-20^{\circ} \mathrm{C}$, no Laboratório de Biologia Molecular da Embrapa Amazônia Ocidental e, ainda assim, os ácidos nucléicos foram suficientemente preservados de degradação.

Foram testados protocolos de extração de ácidos nucléicos desenvolvidos por Edwards et al. (1991); Khanuja et al. (1999) e Doyle \& Doyle (1987). O DNA extraído seguindo o protocolo de Edwards et al. (1991) apresentou-se para a maioria das amostras mais íntegro. Os resultados obtidos quando foram utilizados os métodos descritos por Khanuja et al. (1999) e Doyle \& Doyle
(1987) não apresentaram homogeneidade esperada para amostras coletadas de maneira padronizada. Algumas das soluçōes de ácidos nucléicos preparadas segundo o protocolo descrito por Doyle \& Doyle (1987) sofreram perda rápida de qualidade após a extração, ainda que mantidas a $-20^{\circ} \mathrm{C}$ entre os períodos de realização de experimentos. Este último efeito não ocorreu quando foram aplicados os outros dois protocolos. Além disto, a utilização do protocolo descrito por Edwards et al. (1991) permitiu, freqüentemente, a obtenção de uma maior quantidade de DNA com relação a RNA.

O valor médio para a razão entre os picos de absorvância a $260 \mathrm{~nm}$ e a $280 \mathrm{~nm}$ encontrados para as soluçôes de ácidos nucléicos extraídas de folhas das plantas de pau-rosa foi 1,68. A concentração dos ácidos nucléicos nas soluçōes extraídas de folhas das 130 plantas da Reserva Florestal Adolpho Ducke variou de 65 a 1245 ng. $\mathrm{ml}^{-1}$, para cada 700 a $800 \mathrm{mg}$ de tecidos de folhas.

Os testes para concentração dos componentes visando aprimoramento das reaçôes de PCR indicaram que o emprego de 2,5 unidades de Taq DNA polimerase por reação, entre 2,25 e $3,00 \mathrm{mM}$ de cloreto de magnésio, pelo menos $375 \mathrm{nM}$ de primer decâmero e acima de $100 \mathrm{mM}$ de cada um dos dNTPs foram suficientes para gerar amplificação. A inclusão da BSA a $0,1 \%$ foi essencial para o sucesso das PCR e quantidades de DNA entre 10 e 60 ng por reação não influenciaram o padrão de bandas RAPD obtido.

Definidas as melhores condições para a geração de padrões RAPD para pau-rosa, vinte primers foram avaliados quanto ao número de bandas RAPD geradas e ao polimorfismo verificado para estas bandas utilizando o DNA extraído de quatro plantas. Neste teste, o número médio de bandas produzidas por planta foi de 8,2, sendo 2,7 a média de bandas polimórficas. O número médio de bandas produzidas por RAPD parece ser independente do tamanho do genoma e, em organismos tão diferentes quanto cianobactérias e a soja, observou-se um número médio de cinco bandas por reação (Ferreira \& Grattapaglia, 1994). Então, considerou-se que o RAPD é uma boa técnica para acessar a variabilidade genética também em populações de Pau-rosa, como tem sido para detectar variabilidade em soja (Abdelnoor et al., 1995) já que a média de bandas observadas por planta foi superior a cinco e ocorreu polimorfismo. Os fragmentos amplificados variaram de 185 a 2300 pares de bases.

A reprodutibilidade das bandas produzidas por 11 primers foi testada e a variação na reprodutibilidade foi utilizada para o desenvolvimento de um critério de seleção das bandas componentes dos padrōes RAPD. O padrão de cada banda foi reprodutível de 0 a $100 \%$ das vezes em que foi testado para as mesmas plantas em ocasióes diferentes. Na Figura 1, há exemplos de bandas com grau de reprodutibilidade entre 45 e $100 \%$. A influência de bandas com reprodutibilidade entre 70 e $90 \%$ sobre o cálculo de índices de similaridade (Coeficiente de Jaccard) foi verificada, comparando padrōes produzidos para um mesmo 
grupo de plantas, em duas ocasiōes, nas mesmas condições. Visto que bandas componentes dos padrōes RAPD de cada planta que foram encontradas na primeira ocasiáo em que os experimentos de PCR foram realizados foram comparadas com as bandas dos padrões RAPD gerados na segunda ocasião para as mesmas plantas, era esperado que o número de índices de auto-similaridade com valor 1 (um) fosse igual ao número de plantas testadas. Isto teria ocorrido se não existissem os problemas de reprodutibilidade reconhecidos e inerentes à técnica do RAPD e o DNA de todas as plantas tivesse gerado padrōes idênticos nas duas ocasiōes. Portanto, o número observado de índices de auto-similaridade com valor igual a 1 em cada grupo de dados apresentou variaçôes e aproximou-se mais ou menos dos valores esperados (igual ao total de plantas por grupo) em função da admissão ou não de bandas com reprodutibilidade entre 70 e $90 \%$ para o cálculo, utilizando o Coeficiente de Jaccard ( $F=14,476$ para o teste com 112 padrōes RAPD e 15,873 para o teste com 88 padróes; $\mathrm{P}<$ $0,01)$.

Os contrastes entre o número médio de índices de autosimilaridade iguais a 1 , encontrados para cada tratamento e para o controle foram submetidos ao Teste de Tukey. Houve diferença significativa entre o tratamento 2 (apenas bandas com reprodutibilidade maior ou igual a $90 \%$ admitidas) e os demais $(\mathrm{P} \leq 0,058)$, independente do número de padrōes que constituíram os grupos testados (112 - Figura 2 - ou 88 padrôes RAPD, respectivamente).

A diferença entre o tratamento 3 (apenas bandas com reprodutibilidade maior ou igual a $80 \%$ admitidas) e o tratamento 4 (apenas bandas com reprodutibilidade maior ou igual a $70 \%$ admitidas) apresentou-se mais sutil e dependente do número de padrōes testados. Quando um número variável de padrōes RAPD gerados por cada primer foi comparado a diferença não foi estatisticamente significativa ( $\mathrm{P}=0,16$ - Figura 2$)$. No entanto, quando um número constante de padrōes RAPD gerados por cada primer foi comparado a diferença entre os tratamentos 3 e 4 foi significativa $(P=0,042)$.

A admissão de bandas com grau de reprodutibilidade maior ou igual a $70 \%$ não produziu diferença estatisticamente significativa da admissão de todas as bandas presentes em todos os padrōes, sem aplicação de critérios para seleção (Tratamento 1 - controle), tanto para o grupo de $112(\mathrm{P}=0,784)$ quanto para o grupo de $88(\mathrm{P}=0,842)$ padrōes RAPD.

A aplicação do teste de correlação entre matrizes foi interessante porque permitiu avaliar a eficiência dos critérios aqui descritos para a seleção de bandas também sobre índices de similaridade obtidos para plantas diferentes, ou seja, para todos os índices de similaridade gerados pelas comparações dos padrões RAPD produzidos na primeira ocasião versus aqueles produzidos na segunda ocasião, utilizando os 88 padrões de bandas RAPD. Então, nestas últimas análises, foram incluídos os índices de autosimilaridade (planta 1 na primeira ocasião x planta 1 na segunda ocasião; planta 2 x planta 2 e assim por diante), mas os dados submetidos aos testes de correlação não se limitaram a eles. As matrizes continham os índices de similaridade entre plantas diferentes também (planta $1 \mathrm{x}$ planta 2 na primeira ocasião versus planta $1 \times$ planta 2 na segunda ocasião; planta $1 \times$ planta $3 \mathrm{e}$ assim por diante).

O grau de correlação entre as matrizes de índices de similaridade (Coeficientes de Jaccard) geradas pela admissão apenas de bandas com reprodutibilidade igual ou maior que $90 \%$ foi 0,92 (P para valores aleatórios de $\mathrm{Z}<\mathrm{Z}$ observado $=$ $0,999)$, ou seja, os índices que compuseram as matrizes eram muitíssimo similares. Este grau de correlação entre matrizes foi diminuindo ä medida que critérios mais suaves para a seleção de bandas foram aplicados: quando foram admitidas bandas com reprodutibilidade igual ou maior que $80 \%$, o grau de correlação foi $0,52(P=0,973)$ e quando bandas com reprodutibilidade igual ou maior que $70 \%$ foram admitidas para os cálculos, o grau de correlação foi $0,21(P=0,875)$. O índice de correlação entre matrizes geradas pela admissão de todas as bandas produzidas por todos os primers foi calculado em $0,21(\mathrm{P}=0,821)$, o mesmo valor encontrado com a aplicação do critério de admissão de bandas com reprodutibilidade de $70 \%$. Estes resultados corroboram o que já tinha sido discutido com relação ao número médio de índices de auto-similaridade iguais a 1 produzidos pela aplicação dos critérios para seleção de bandas. Então, tomando os resultados de todas as análises, conclui-se que a eliminação de bandas com reprodutibilidade menor que $80 \%$ pode aproximar os resultados observados daquilo que seria ideal: que padrōes RAPD para um mesmo conjunto de indivíduos sejam

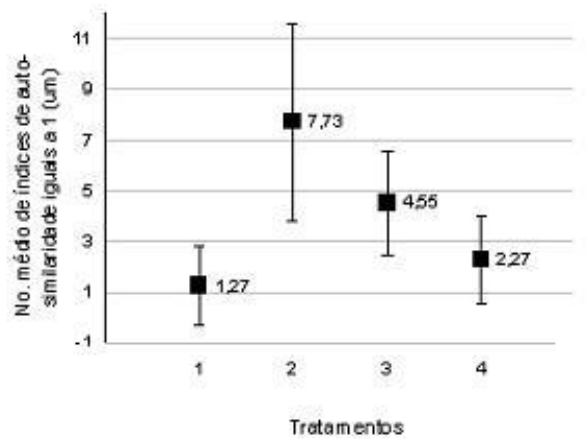

Figura 2 - Número médio de índices de auto-similaridade com valor 1 e desvios das médias, observados para quatro tratamentos dispensados a 112 padrões de bandas RAPD, sendo variável o número de padrões produzidos por cada um de 11 "primers" (Material e Métodos 2.4 a). Tratamento 1 (controle): todas as bandas geradas foram admitidas para 0 cálculo; Tratamento 2: apenas bandas com reprodutibilidade igual ou maior que $90 \%$ admitidas; Tratamento 3: apenas bandas com reprodutibilidade igual ou maior que $80 \%$ admitidas; Tratamento 4: apenas bandas com reprodutibilidade igual ou maior que $70 \%$ admitidas (Embrapa Amazônia Ocidental - Manaus/ $A M)$. 
reproduzidos perfeitamente em todas as ocasiōes que forem gerados.

\section{CONCLUSÕES}

A geração de padrōes RAPD para Pau-rosa foi possível para folhas coletadas em tubos de polietileno com grânulos de sílica gel, armazenadas, até 10 dias depois da coleta, a $-20^{\circ} \mathrm{C}$, sendo o DNA extraído com tampão de SDS;

A aplicação do critério, cujo desenvolvimento foi descrito neste trabalho, para a eliminação de bandas RAPD com grau de reprodutibilidade menor que $90 \%$, influenciou significativamente o valor calculado para os índices de similaridade, independentemente do número de padrōes RAPD gerados por primer;

A eliminação de bandas RAPD com grau de reprodutibilidade menor que $80 \%$, influenciou, significativamente, o valor calculado para os índices de similaridade, apenas quando número constante de padrōes RAPD foi gerado por cada primer ;

A eliminação de bandas RAPD com grau de reprodutibilidade menor que $70 \%$ não diferiu estatisticamente da admissão de todas as bandas, reprodutíveis ou não, para o cálculo de índices de similaridade, independentemente do número de padrôes RAPD gerados por primer.

\section{AGRADECIMENTOS}

Ao Fundo Nacional do Meio Ambiente e ao PRODETAB, pelo suporte financeiro. À Fundação de Apoio Institucional Muraki pela administração de parte dos recursos financeiros. Ao Dr. Charles Roland Clement (INPA) e a Doriane P. Rodrigues. Ao Dr. Wenceslau Teixeira e a Adauto Maurício Tavares, Pesquisadores da Embrapa Amazônia Ocidental, pelas sugestōes referentes aos métodos de análise estatística. À Jeferson Chagas da Cruz, Técnico de Nível Médio, Laboratório de Biotecnologia Vegetal, Embrapa Amazônia Ocidental.

\section{BIBLIOGRAFIA CITADA}

Abdelnoor, R.V.; Barros, E.G.; Moreira, M.A. 1995. Genetic diversity within the brazilian soybean germoplasm by the Random Amplified Polymorphic DNA technique and comparative analysis with pedigree data. Rev. Bras. Genet., 18: 265-273.

Almeida, C.A.S.; Bomvicino, C.R.; Lachtermacher, M.; Moreira, M.A.M.; Renata, O.; Deuánez, H.N. 2001. Técnicas de avaliação da diversidade genética. In:Garay, I.; Dias, B. (Eds.) Conservação da biodiversidade em ecossistemas tropicais. Editora Vozes. 430pp.

Bussel, J.D. 1999. The distribution of random amplifies polymorphic DNA (RAPD) diversity amongst populations of Isotoma petrea (Lobeliaceae). Mol. Ecol., 8: 775 - 789.
Clark, A. G.; Lanigan, C. M. S. 1993. Prospects for estimating nucleotide divergence with RAPDs. Mol. Biol. Evol., 10: 10961111.

Chase, M.W.; Hills, H.H. 1991. Silica gel: an ideal material for filed preservation of leaf samples for DNA studies. Taxon, 40: 215220.

Cruz, C.D. 2001. Programa Genes - versão Windows. Aplicativo computacional em Genética e Estatística. UFV. p. 169-188.

Doyle, J.J.; Doyle, J.L. 1987. A rapid DNA isolation procedure from small quantities of fresh leaf tissue. Phytochem. Bull., 19: 11-15.

Edwards, K; Johnstone, C.; Thompsons, C. 1991. A simple and rapid method for the preparation of plant genomic DNA for PCR analysis. Nucl. Ac. Res., 19: 1349.

Ferreira, M.E.; Grattapaglia, D. 1994. Introdução ao uso de marcadores moleculares em análise genética. Embrapa - Cenargen, Brasília. 220pp.

Geburek, T. 1997. Isozymes and DNA markers in gene conservation of forest tree. Biodivers. Conserv., 6: 1639-1654.

Grattapaglia, D. 1997. Pseudo - testcross mapping strategy using RAPD markers. In: Micheli, M.R;Bova, R. (Eds.) Fingerprinting methods based on arbitrarily primer PCR. Springer Verlag. Berlin. p. 201-217.

Hall, P.; Walker, S.; Bawa, K. 1996. Effects of forest fragmentation on genetic diversity and mating system in a tropical tree, Pithecellobium elegans. Conserv. Biol., 10: 757-768.

IBAMA. 1992. 1a Portaria $N^{\circ} 37$ de 3 de abril de 1992.

Jones, C.J.; Edwards K.J.; Castaglione, S.; Winfield, M.O. Sala, F.; van de Wiel, C.; Bredemeijer, G.; Vosman, B.; Matthes, M. Daly, A.; Brettschneider, R.; Bettini, P.; Buiatti, M. ; Maestri, E. ; Malcevschi, A.; Marmiroli ,N.; Aert, R. Volckaert, G.; Rueda, J.; Linacero, R.; Vazquez, A.; Karp, A. 1997. Reproducibility testing of RAPD, AFLP and SSR markers in plants by a network of European laboratories. Mol. Breed., 3: 381-390.

Khanuja, S.P.S.; Shasany, A.K.; Daarokar, M.P.; Kumar, S. 1999. Rapid isolation of DNA from the dry and fresh samples of plants producing larger amounts of secondary metabolites and essential oils by modified CTAB procedures. Plant Mol. Biol. Rep., 17: 17.

Lynch, M; Milligan, B.G. 1994. Analysis of population genetic structure with RAPDS markers. Mol. Ecol., 3: 91-99.

Meunier, J.R.; Grimont P.A.D. 1993. Factors affecting reproducibility of random amplified polymorphic DNA fingerprinting. Res. Microbiol., 144: 373-379.

Mitja, D.; Lescure, J.P. 2000. Madeira para perfume: qual será o destino do Pau-rosa? In: Emperaire, L. (Coord). A floresta em jogo. O extrativismo na Amazônia Central. Editora UNESP, São Paulo, São Paulo. p. 93-102.

Mullis, K.; Faloona, F. 1987.Specific synthesis of DNA in vitro via a polymerase catalysed chain reaction. Methods Enzymol., 55:335350.

Péres, T.; Albornoz, J.; Domínguez, A. 1998. An evaluation of RAPD fragment reproducibility and nature. Mol. Ecol., 7: 1347-1357. 
Vial-Debas, C. 2000. Da tora ao linalol: uma interface economia ecologia. In: Emperaire, L. (Coord). A floresta em jogo. $O$ extrativismo na Amazônia Central. Editora UNESP, São Paulo. p. 183-190.

Williams, J.G.; Kubelik, A.R.; Livak, K.J.; Rafalski, L.A.; Tingey, S.V. 1990. DNA polymorphism amplifies by arbitrary primers are useful as genetic markers. Nucleic Acids Res., 18: 6531-3535.
Young, A.; Boyle, T.; Brown, T. 1996. The population genetic consequences of habitat fragmentation for plant. Trends Ecol. Evol., 11. 413-416.

Yu, K.; Pauls, K.P. 1992. Optimization of the PCR program for RAPD analysis. Nucleic Acids Res., 20: 2606.

Recebido em 12/07/2005

Aceito em 16/02/2007 
